\title{
Stereotomy 2.0: High-Performance Eloquence
}

\section{Patrik Schumacher ${ }^{1}$}

Published online: 17 September 2018

(c) Kim Williams Books, Turin 2018

\begin{abstract}
Patrik Schumacher reflects on the role and potential of Stereotomy 2.0 within the larger context of parametricism.
\end{abstract}

Keywords Stereotomy 2.0 · Parametricism · Architectural research $\cdot$ Rule-based design

This special issue of the Nexus Network Journal is a gem and 'must read' for anybody affiliated to the movement of parametricism, and more generally for any aspiring architect who wants to join our discipline's quest for continuous advancement through design research and experimental construction. It allows us to appreciate both the resourceful historical depth of our discipline and our current historical point of exploratory take-off into novel, computationally and scientifically empowered ventures of architectural discovery.

The articles collected here meet the highest academic and scientific standards and the design research work presented and explained within them are a real delight due to their originality and beauty. This coincidence of scholarly depth, scientific rigour and awe-inspiring beauty is, in fact, no coincidence at all: if aesthetic values and sensibilities are no irrational distractions from the pursuit of vital building performances but guide their intuitive grasp, then we should expect this coincidence. Beauty is indeed the promise of performance, and the sensibilities that guide us here are those which also allow us to appreciate the endless forms of nature, organic and inorganic. It is the intelligent, scientifically guided appropriation of the principles of self-organizing and self-optimizing morphogenesis we find in nature that has been guiding the advances in building related computational geometry in general. However, in this issue we witness the scientifically guided appropriation and extension of forgotten historical treasures. The long history of human construction efforts forms its own deep, congenial resource of painstakingly accumulated building form discoveries, with respect to both global form and tectonic detail. Some of these

Patrik Schumacher

patrik.schumacher@zaha-hadid.com

1 Zaha Hadid Architects, 10 Bowling Green Lane, London EC1R 0BQ, UK 
discoveries had already been rationalized and turned into explicit competencies via theoretical as well as practical-instructive treatises hundreds of years ago. It's a thrill to read in these pages how the re-discovery and congenial expansion of 'ancient', forgotten construction knowledge and geometric competencies has fuelled the contemporary advances displayed here. Further, the competencies preserved in those old treatises reappear in expanded and enhanced form, ready to use, as digital design tools. This - together with the experimental structures-shows the real commitment to innovative practice. This is also evident in the commitment to new materials and new computationally empowered fabrication processes.

Stereotomy, reborn as 'Stereotomy 2.0' is expanding its formal and material range and thus its scope of application. This research agenda is an integral part of a larger research community and architectural movement dedicated to the systematic integration of material logics as well as engineering and fabrication rationales into the very constitution of its tools and processes, and thus of its formal repertoire. This method of pre-constraining the search space of the design exploration is viable without undue loss of vital design freedom due to the increasing diversity of the processes at hand, as well as the fecund parametric variability of each process. What is gained is not only guaranteed construction feasibility but a new formal rigour with characterful results that can only be expected from such a rulebased approach to design. What emerges here is a new compelling language for architectural articulation that affords a diverse set of types of tectonic expression, with each type affording an internally variable and adaptive family of forms which remain unified and identifiable across their range of variations. Further, the various tectonic types may form a system and overall language that exhibits a legible coherence across otherwise rather distinct tectonic ontologies, each with its typical, visually recognisable geometric DNA. Compression-only shells with characteristically optimised voussoir configurations are legibly distinct from tailored tensile membranes, and from the cone-based surfaces generated via curved folding of sheet materials, or from the ruled surfaces generated by robotic hotwire cutting. However, all these types visibly share the same rule-based rigour, parametric variability and thus adaptive capacity, i.e. all these approaches congeal into a coherent new language for architecture, the language of a new style which I would like to call 'tectonism', understood as the latest, and in my view most sophisticated and productive, subsidiary style within the epochal style of parametricism. While the technological advantages of this movement are obvious enough, I would like to emphasize here the expressive fecundity and thus communicative capacity of this movement and style. The rule-based variation within each system will be naturally eloquent due to the possibility of inferring the input conditions from the output results inherent in rule-based designs. The formal identities of the various tectonic systems might be orchestrated into an eloquent system of differential programme characterisations. After all, architecture's primary responsibility is the innovation of the built environment's social functionality, in contrast to engineering's responsibility for technical functionality. The social functioning of buildings and spaces depends crucially on their legibility and communicative capacity, and in this respect Stereotomy 2.0, as tectonism in general, is very promising indeed. 
Patrik Schumacher is principal of Zaha Hadid Architects and has been leading the firm since Zaha Hadid's passing in March 2016. He studied philosophy, mathematics and architecture in Bonn, Stuttgart and London. He received his Diploma in architecture in 1990. In 1999 he completed his Ph.D. at the Institute for Cultural Science, Klagenfurt University. He has been a partner in ZHA since 2003. In 2010, together with Zaha Hadid, he won the Stirling Prize for excellence in architecture, for MAXXI in Rome. $\mathrm{He}$ is an academician of the Berlin Academy of Arts. In 1996 he founded the Design Research Laboratory at the Architectural Association in London, where he continues to teach. He lectures worldwide and is currently a guest professor at Harvard's GSD. In 2008 he coined the term 'parametricism' and has since published a series of manifestos promoting parametricism as the new epochal style for the twenty-first century. He recently published his two-volume theoretical opus magnum, The Autopoiesis of Architecture (Wiley, 2011-2012). 